\title{
KEBUDAYAAN SEBAGAI SUATU KOMITMEN KESADARAN DIRI UNTUK MENGANGKAT TRADISI SEBAGAI KONSEP CONTEMPORARY VERNACULAR PADA INTERIOR DAN ARSITEKTUR
}

\author{
Doni Morika \\ Jurusan Desain Interior, Fakultas Komunikasi dan Multimedia, BINUS University \\ Jln. K.H. Syahdan No. 9, Kemanggisan, Palmerah, Jakarta Barat 11480 \\ donimorika@binus.ac.id
}

\begin{abstract}
Humans are part of the natural environment or, in the context of human culture to use reason and mind to be able to coexist with nature. But the more advanced capabilities of human thought and the further development of technologies that make, the pattern of human origin in order to live in harmony with nature the more degenerate into an attempt to conquer nature. Associated with the times, 'needs' and 'demand' from the user will be higher, both in terms of function and aesthetics. A design must be able to also follow the movement pattern of the trend that occurred in the community to be recognized. Through discourse Contemporary Vernacular Architecture in the Interior and revealed in some design work, as object of study is the existence of a work done by several designers and architects in Indonesia as a commitment to self-awareness to lift a tradition contained in Sundanese culture.
\end{abstract}

Keywords: interiors, architecture, culture, aesthetics, contemporary vernacular

\begin{abstract}
ABSTRAK
Manusia merupakan bagian dari lingkungan atau alam, dalam konteks kebudayaan manusia menggunakan akal dan pikirannya untuk dapat hidup berdampingan dengan alam. Tetapi semakin maju kemampuan berpikir manusia dan semakin jauh pengembangan teknologi yang dibuatnya, pola asal manusia untuk dapat hidup selaras dengan alam semakin menyimpang menjadi usaha untuk menaklukan alam. Terkait dengan perkembangan zaman, 'needs' dan 'demand' dari pengguna akan semakin tinggi, baik dari segi fungsi maupun estetika. Sebuah design harus mampu pula mengikuti pola pergerakan dari trend yang terjadi di masyarakat untuk dapat diakui. Melalui wacana Contemporary Vernacular dalam Interior dan Arsitektur yang terungkap dalam beberapa karya desain yang dijadikan objek studi adalah adanya suatu usaha yang dilakukan oleh beberapa Desainer dan Arsitek yang ada di Indonesia sebagai suatu komitmen kesadaran diri untuk mengangkat suatu tradisi yang terdapat di dalam kebudayaan masyarakat Sunda.
\end{abstract}

Kata Kunci: interior, arsitektur, budaya, estetika, contemporary vernakular 


\section{PENDAHULUAN}

Indonesia sebagai negara kepulauan yang terdiri dari berbagai jenis suku bangsa, sangat kaya akan berbagai macam ragam budaya yang dihasilkan oleh masyarakatnya. Interior dan Arsitektur di Indonesia pada awalnya muncul sebagai jawaban dari kebutuhan yang timbul dalam kehidupan manusia, berwujud dalam bentuk shelter sebagai tempat untuk bernaung dan berlindung dari segala gangguan luar, tumbuh secara alami dan intuitif berupa produk yang dihasilkan oleh seluruh masyarakat, seperti burung membangun sangkarnya. Kemudian berkembang, sehingga pada saat ini tidak hanya sebagai tempat bernaung, tetapi juga untuk mewadahi aktifitas yang cukup beragam. Keadaan tersebut merupakan tradisi yang ada pada seluruh belahan dunia, terutama untuk belahan dunia bagian Timur (Asia).

Berlawanan dengan proses tersebut, tentu saja ada paradigma kontemporer, suatu tradisi modern, dimana karya Interior dan Arsitektur secara jelas lahir sebagai upaya idiosyncratic individu. Tradisi tersebut dimulai pada zaman Renaissance di Eropa, dan sekarang pada akhir abad ke-20 telah menyebar ke seluruh bagian dunia. Indonesia sebagai negara yang berada dalam kawasan Asia merupakan negara yang berada pada suatu persimpangan, dimana keberadaanya ini berada di antara dua paradigma yaitu paradigma Vernakular sebagai warisan budaya dengan segala unsur lokalitasnya, serta paradigma Kontemporer sebagai suatu pengaruh globalisasi yang tidak bisa kita bendung.

Kajian ini tidak untuk mempermasalahan pentingnya semangat lokalitas yang pada saat ini masih diperdebatkan. Tetapi ingin memperlihatkan fenomena yang sedang berkembang di Asia umumnya dan Indonesia pada khususnya, tentang perhatian akan nilai-nilai lokal dimana suatu desain berada. Seperti pendapat Edward H.Y Wong, presiden Singapore Institute of Architecture; "Good building design has the ability to blend well with the environment and surroundings, taking into consideration the climatic and cultural factors. Suatu desain yang baik memiliki kemampuan untuk menyatu dengan dengan kondisi sekitarnya, memperhatikan faktor-faktor lingkungan alam seperti Iklim dan faktor Budaya.

\section{METODE}

Tahapan-tahapan kajian yang dilakukan pada objek studi yang ada diharapkan dapat menjembatani penulisan secara keseluruhan, untuk menjawab permasalahan desain yang ada. Metoda kajian objek studi dibagi kedalam tiga bagian, yang terdiri dari: (1) pengungkapan bentuk arsitektur, pembahasan secara garis besar terhadap objek Arsitektur yang diamati, baik bentukan eksterior, interior serta detail yang ada; (2) keterkaitan aspek fisik pada bentukan arsitektur, pembahasan mengenai keterkaitan objek Arsitektur yang diamati dengan aspek fisik yang terdapat pada konteks lokal Sunda, meliputi keterkaitan bentukan arsitektur dengan tapak dan lingkungan, iklim serta material; dan (3) keterkaitan aspek non-fisik pada bentukan interior dan arsitektur, pembahasan mengenai keterkaitan objek interior dan arsitektur yang diamati dengan aspek non-fisik yang terdapat pada konteks lokal Sunda, meliputi keterkaitan bentukan interior dan arsitektur dengan sistem religi dan kepercayaan serta sistem kemasyarakatan.

Hasil yang diperoleh dari ketiga kajian tersebut diharapkan dapat menjawab pertanyaan tentang bagaimana pengungkapan tradisi yang terdapat pada konteks lokal Sunda pada bangunan masa kini serta sejauh mana keterkaitan bentukan Arsitektur dengan konteks lokal yang ada baik dari segi fisik maupun non-fisik. 


\section{HASIL DAN PEMBAHASAN}

\section{Kajian Resor Kampung Sampireun}

Resor Kampung Sampireun mulai beroperasi pada bulan Januari 1999. Sebuah resor bernuansa perkampungan Sunda, berada di ketinggian $\pm 1000 \mathrm{~m}$ di atas permukaan laut, berlokasi di Kampung Ciparay, Desa Sukakarya, Kecamatan Samarang, Kabupaten Garut, Jawa Barat. Memiliki luas area sebesar 3,5 hektar, termasuk luas Situ Sampireun sendiri dengan mata air alaminya. Perencanaannya dilakukan oleh Arsitek Ir. Djembar Nugraha dengan dibantu Arsitek Lansekap Ir. Ami Zamzami.

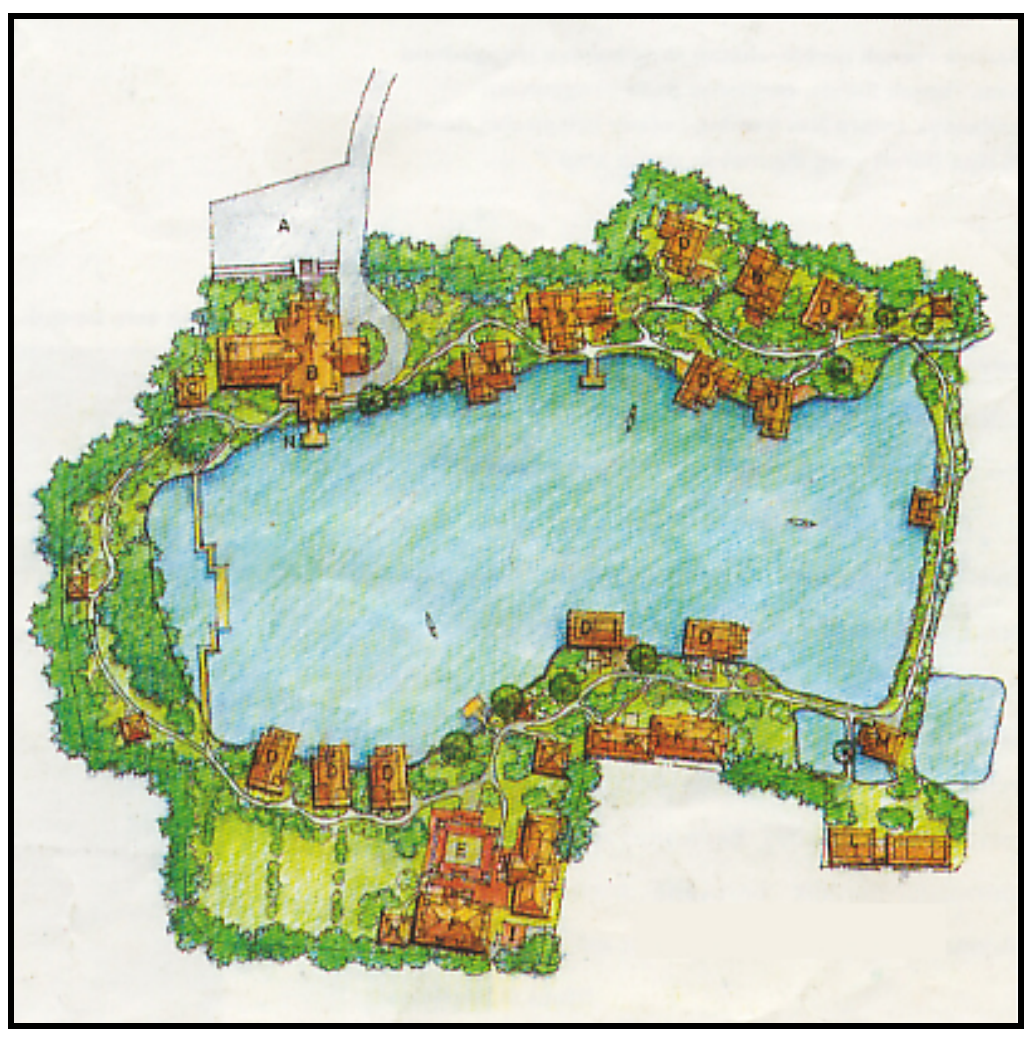

Gambar 1 Site plan Kampung Sampireun (Sumber : Dokumentasi Arsitek)

Kampung Sampireun diambil dari nama Situ (Danau) Sampireun yang memiliki pengertian ‘tempat singgah' dalam bahasa Sunda, dengan sumber mata air yang cukup besar yang dipergunakan oleh masyarakat setempat untuk mengairi sawah-sawah mereka. Resor kampung Sampireun ini mewadahi aktifitas utama hotel yang dilengkapi dengan 13 cottage terdiri dari 7 unit suite Kalapalua, 4 unit suite Kurjati, 1 unit suite Waluran dan 1 unit suite Manglayang, restoran, warung kopi, meeting room, taman yang bisa digunakan untuk pesta kebun, serta kolam renang dan spa.

\section{Pengungkapan Bentuk Arsitektur}

Dilihat dari rencana tapaknya nampak bahwa Resor Kampung Sampireun ini mencoba untuk merepresentasikan tatanan kampung Sunda dengan elemen-elemen yang terdapat di dalamnya. 


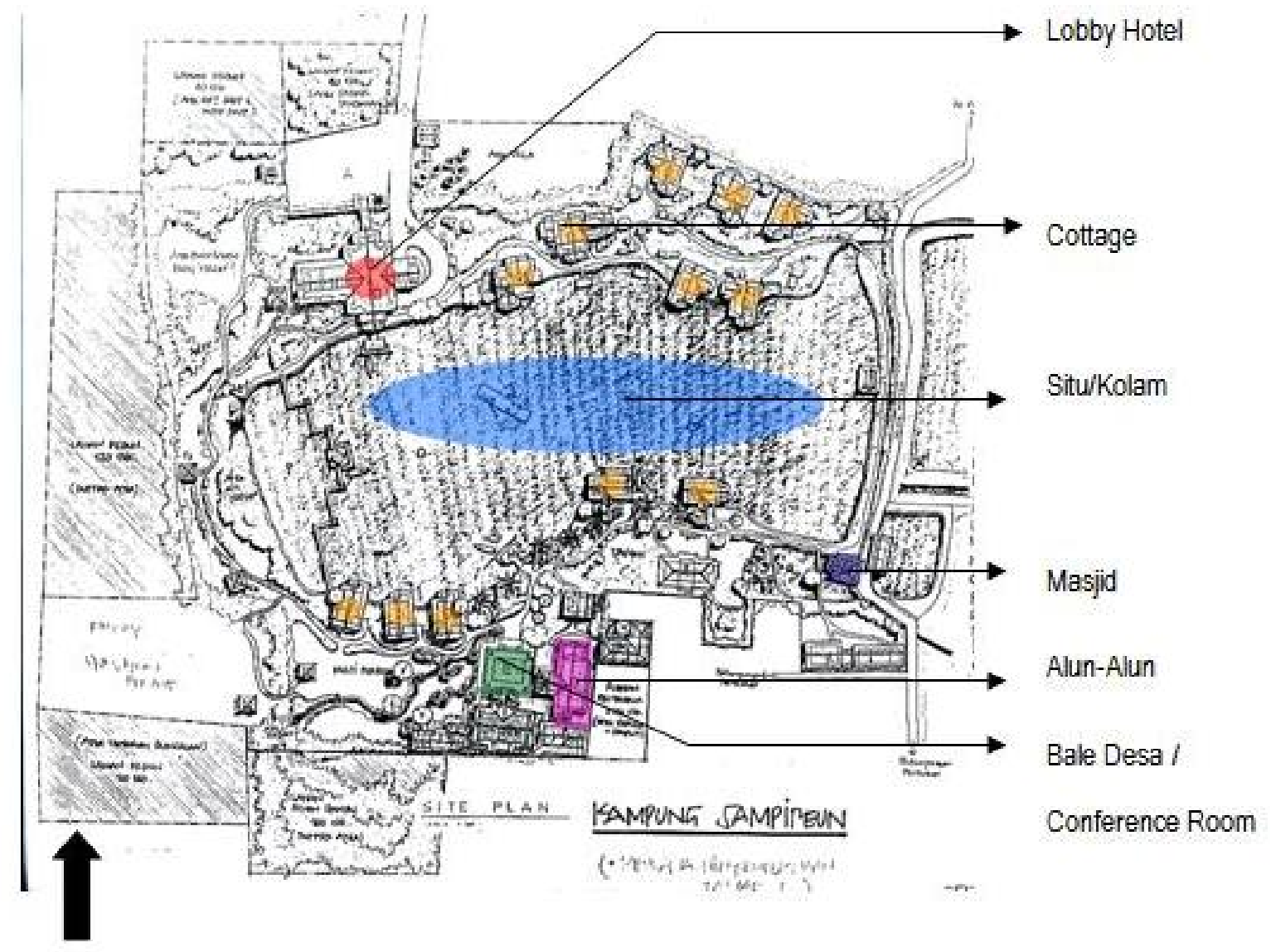

Gambar 2 Site plan cottage Kampung Sampireun Sumber: Gambar Kerja Proyek Resor Kampung Sampireun, 1998

Namun dalam perletakannya mengalami penyesuaian seperti pada perletakan mesjid. Perletakan mesjid tetap di ujung sebelah barat, tetapi letaknya terpisah dengan alun-alun dan bale desa, padahal biasanya berada berdekatan dengan alun-alun dan bale desa. Hal ini disebabkan agar masjid ini bisa juga dipakai oleh penduduk yang ada di sekitar resor ini. Unsur aktifitas dan fungsi yang ada di resor ini merupakan penerapan dari aktifitas dan fungsi yang ada pada suatu kampung sunda dengan beberapa penyesuaian dan penambahan fungsi yang disesuaikan dengan kebutuhan dasar suatu hotel, di antaranya yaitu penyesuaian bentukan bale desa menjadi lobi hotel (Gambar 3) dan conference room (Gambar 4), lalu bentukan rumah penduduk menjadi cottage, dan penambahan fungsi baru seperti spa (Gambar 5) dan kolam renang (Gambar 6).

Pada budaya Sunda, bale desa difungsikan sebagai pusat informasi. Dalam kaitannya dengan hal itu, bangunan Lobi Hotel pada resor Kampung Sampireun pun berfungsi seolah-olah seperti bale desa pada suatu lingkungan binaan mengingat fungsi pada Lobi juga sebagai pusat informasi, dengan bentuk yang lebih terbuka tanpa dinding penutup. Selain itu, perletakan serta bentuk bangunan cottage pada resor Kampung Sampireun dibuat sebagai representasi pemukiman penduduk di suatu kampung dengan sistemnya yang berkelompok. 


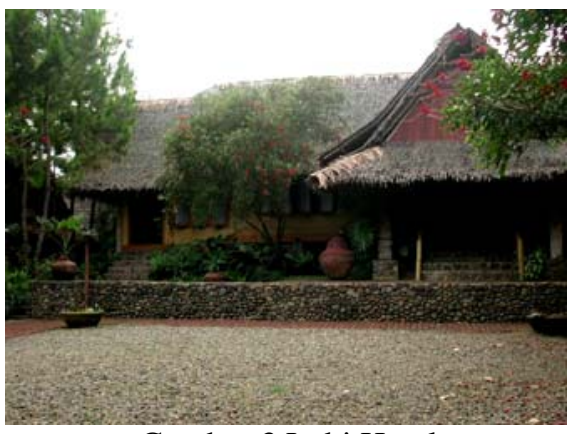

Gambar 3 Lobi Hotel

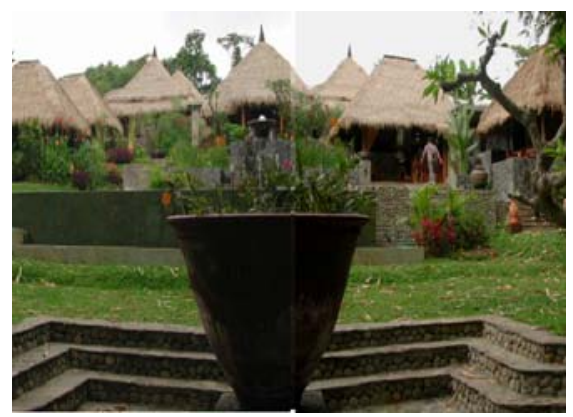

Gambar 5 Spa

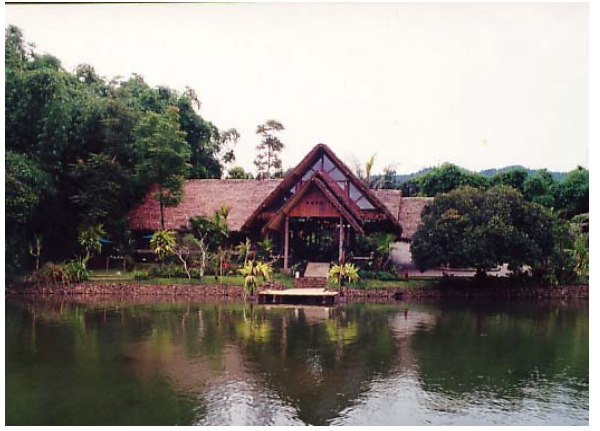

Gambar 4 Conference Room

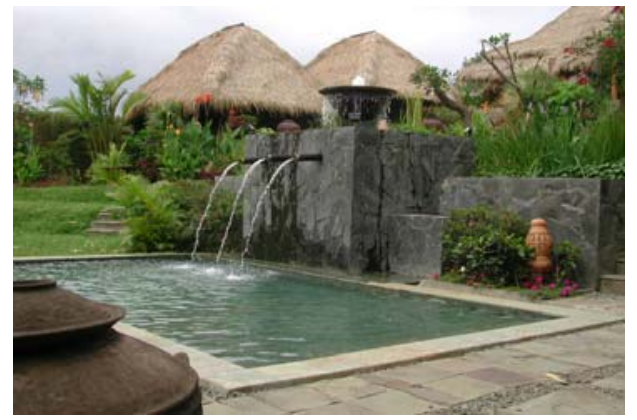

Gambar 6 Kolam Renang

Dalam upaya menjadikannya sebuah hotel, dilakukan penambahan berbagai fasilitas modern yang tentunya tidak ada di dalam konsep sebuah kampung. Namun penambahan fungsi tersebut diupayakan senantiasa berada dalam lingkup konsep semula yaitu sebuah kampung Sunda. Bangunanbangunan yang ada dalam kompleks resor ini sebagian besar mengikuti bentukan bangunan tradisional Sunda dengan karakteristik suhunan panjang, serta konstruksi panggung. Namun bentukan atap serta massa bangunan mengalami modifikasi, disesuaikan tuntutan kontur, fungsi serta estetika sebagai tuntutan utama dari suatu Hotel Resor. Keempat jenis atap dengan modifikasi atap umpak pada bangunan cottage. Dari kiri ke kanan tipe Waluran, Kalapalua, Kurjati, Manglayang.
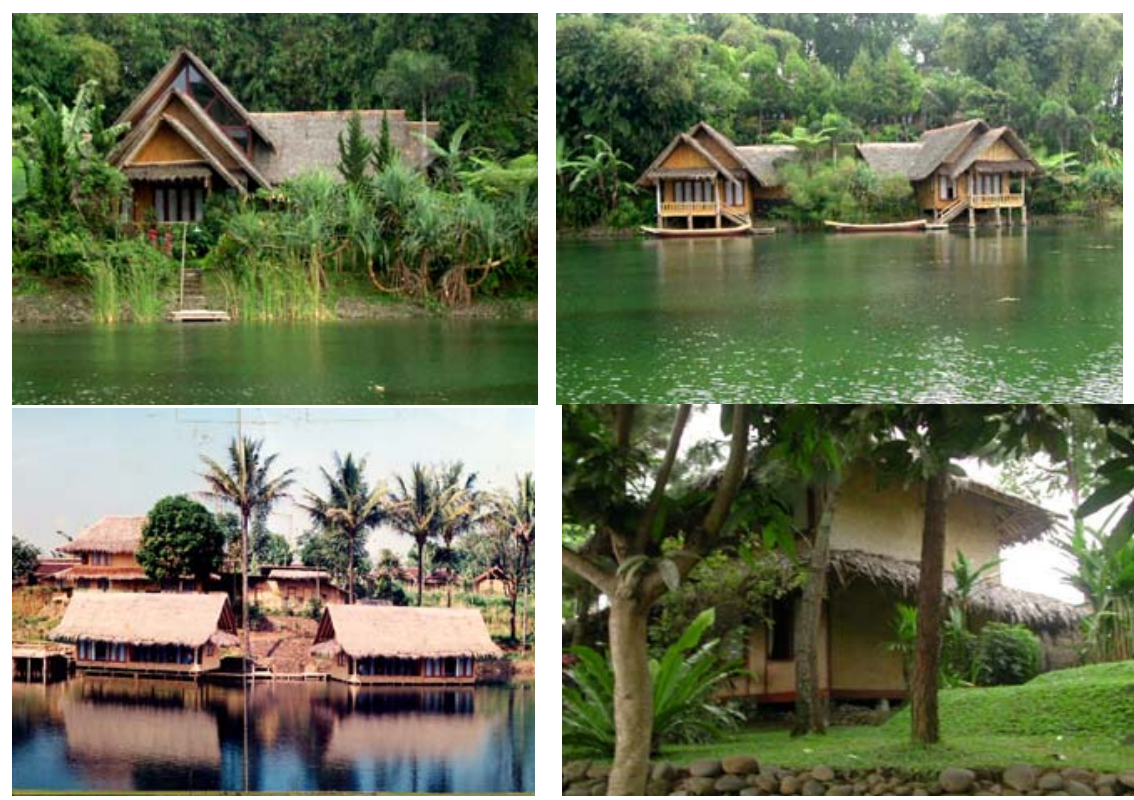

Gambar 7 Karakter/bentuk dari atap bangunan. Sumber: Dokumentasi pribadi 


\section{Keterkaitan Aspek Fisik dalam Arsitektur}

Keberadaan Resor Sampireun ini berada di tengah perkampungan rakyat Desa Sukakarya. Pencapaian setelah dari jalan raya menuju Resor ini melewati perumahan penduduk, hal ini disebabkan karena keberadaan Resor yang berada di ujung jalan. Jalan penduduk yang menghubungkan Resor dengan Jl. Raya Samarang difinish dengan batu cor sikat, hal dilakukan agar pengunjung merasa diarahkan dalam pencapaian menuju resor ini. Secara fisik keberadaan kompleks resor ini terlihat membaur dengan keberadaan desa Sukakarya sekitarnya. Hal ini selain terlihat dari skyline atap kompleks resor ini, juga terlihat dari material yang digunakan. Batas fisik yang dipergunakan untuk membatasi Kompleks resor dengan lingkungan luar hanya dengan menggunakan tanaman semak serta pagar bambu, dimana ada bagian pagar yang bisa dibuka dan ditutup. Hal ini memungkinkan adanya akses bagi masyarakat sekitar untuk mempergunakan mesjid yang ada di kompleks Resor ini.

Keberadaan Resor Kampung Sampireun dengan lingkunga sekitar (Sumber : Dokumentasi Arsitek)

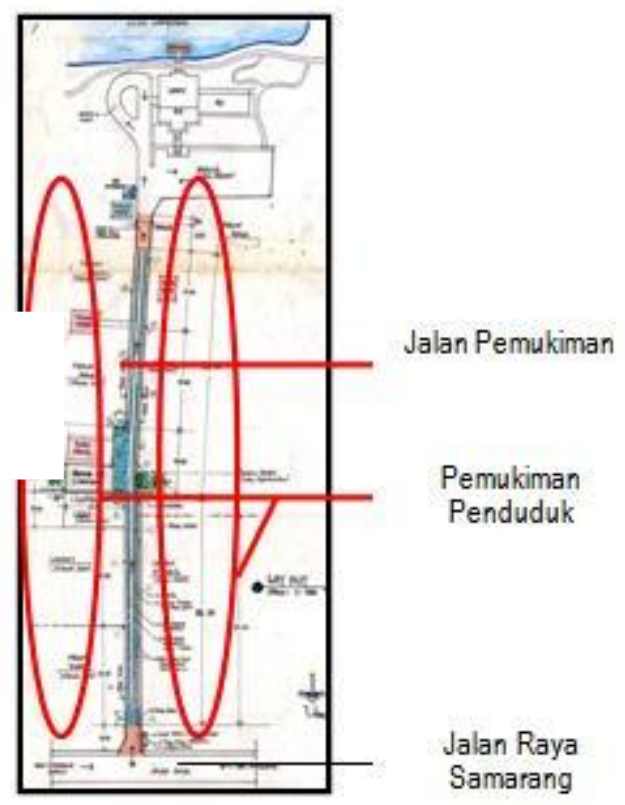

Gambar 8 Pencapaian menuju Resor Kampung Sampireun Sumber: Dokumentasi Arsitek
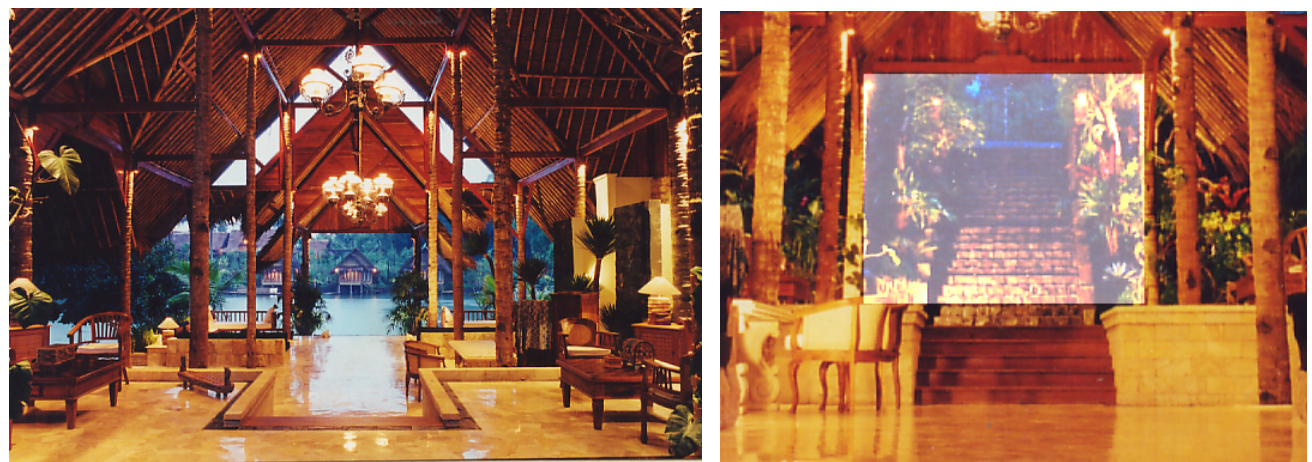

Gambar 9 Hall penerima serta tangga pencapaian dari area parkir pada bangunan lobi hotel Sumber: Dokumentasi pribadi

Dari arah tempat parkir kita akan melihat entrance utama hotel menuju lobi hotel yang posisinya lebih bawah dari level tempat parkir, mengikuti bentuk kontur yang makin rendah ke arah 
situ. Setelah menuruni anak tangga kita akan melihat hall lobi yang cukup terbuka tanpa dinding penutup, sehingga dari sana kita bisa melihat view Situ Sampireun serta bangunan cottage yang ada di seberangnya. Pola pencapaian menuruni anak tangga mengingatkan kita pada pada pencapaian yang ada di kampung naga, Kabupaten Tasikmalaya, meskipun jumlah anak tangga yang harus dituruni tidak sebanyak yang ada di kampung Naga tersebut. Tahapan sekuensial yang terlebih dahulu melewati elemen air untuk menuju cottage mengingatkan kita pada pencapaian menuju pemukiman yang terdapat di kampung-kampung Sunda.

Keberadaan existing situ ini terlihat menjadi elemen utama sebagai benang merah dari resor ini, sebagai pusat orientasi dari seluruh massa bangunan cottage. Keberadaan elemen air yang dekat dengan konteks lokal Sunda juga dimasukan lewat keberadaan saluran-saluran air di sekitar tapak yang bermuara langsung ke Situ Sampireun ini.

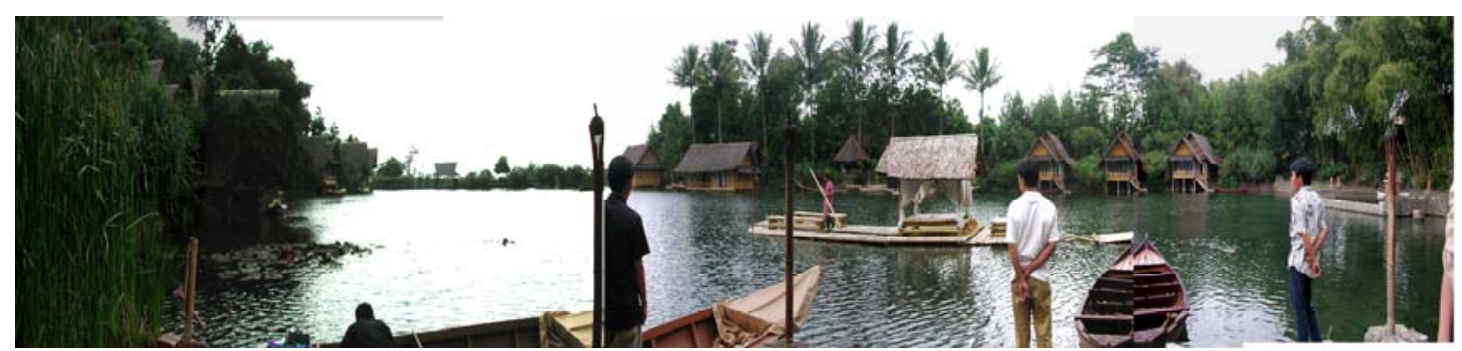

Gambar 10 View dari lobi ke arah situ dan penginapan

Sumber: Dokumentasi pribadi

Pada Resor Kampung Sampireun ini pemanfaatan material alam lokal banyak diterapkan dalam berbagai elemen desain, pada area lobi misalnya kita bisa melihat pemanfaatan berbagai macam material alam lokal. Diantaranya seperti rangka atap utama yang diekspos dengan menggunakan material lokal seperti kayu, kaso dan reng yang menggunakan material bambu, serta kolom-kolom utama penahan atap yang menggunakan batang pohon kelapa, yang dalam jangka waktu tertentu mengalami penggantian, untuk menjaga kekuatan daya dukungnya.

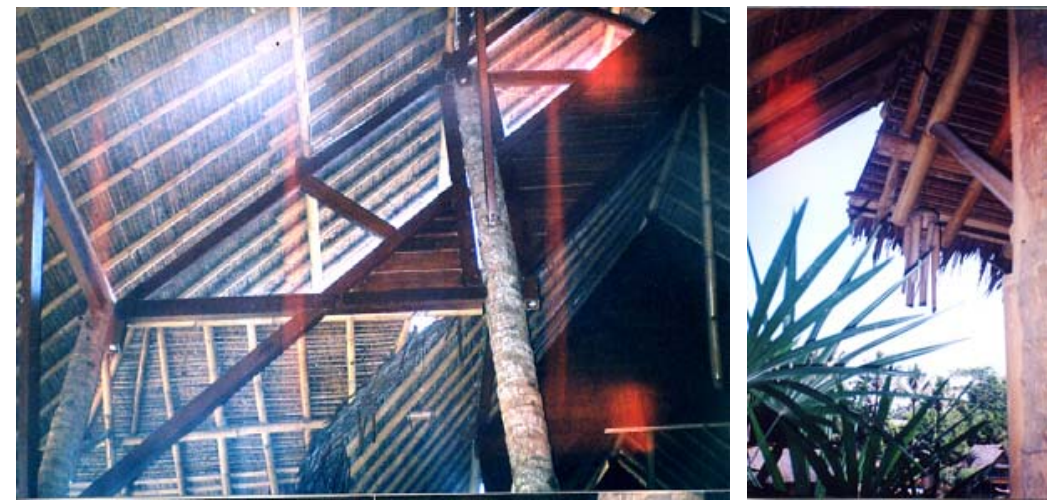

Gambar 11 Penggunaan material kayu kelapa tanpa finshing sebagai kolom struktur Sumber: Dokumentasi pribadi

Keberadaan existing site yang banyak ditumbuhi tanaman bambu, dimanfaatkan secara optimal untuk digunakan kedalam berbagai elemen desain. Mulai dari elemen rangka atap, dinding penutup (anyaman bilik dan sasag), jembatan, sarana transportasi (rakit), street furnitur, sampai dengan furnitur yang digunakan di dalam ruangan maupun yang diluar ruangan. Material bambu ini merupakan material khas yang terdapat pada konteks fisik lokal daerah Sunda. 


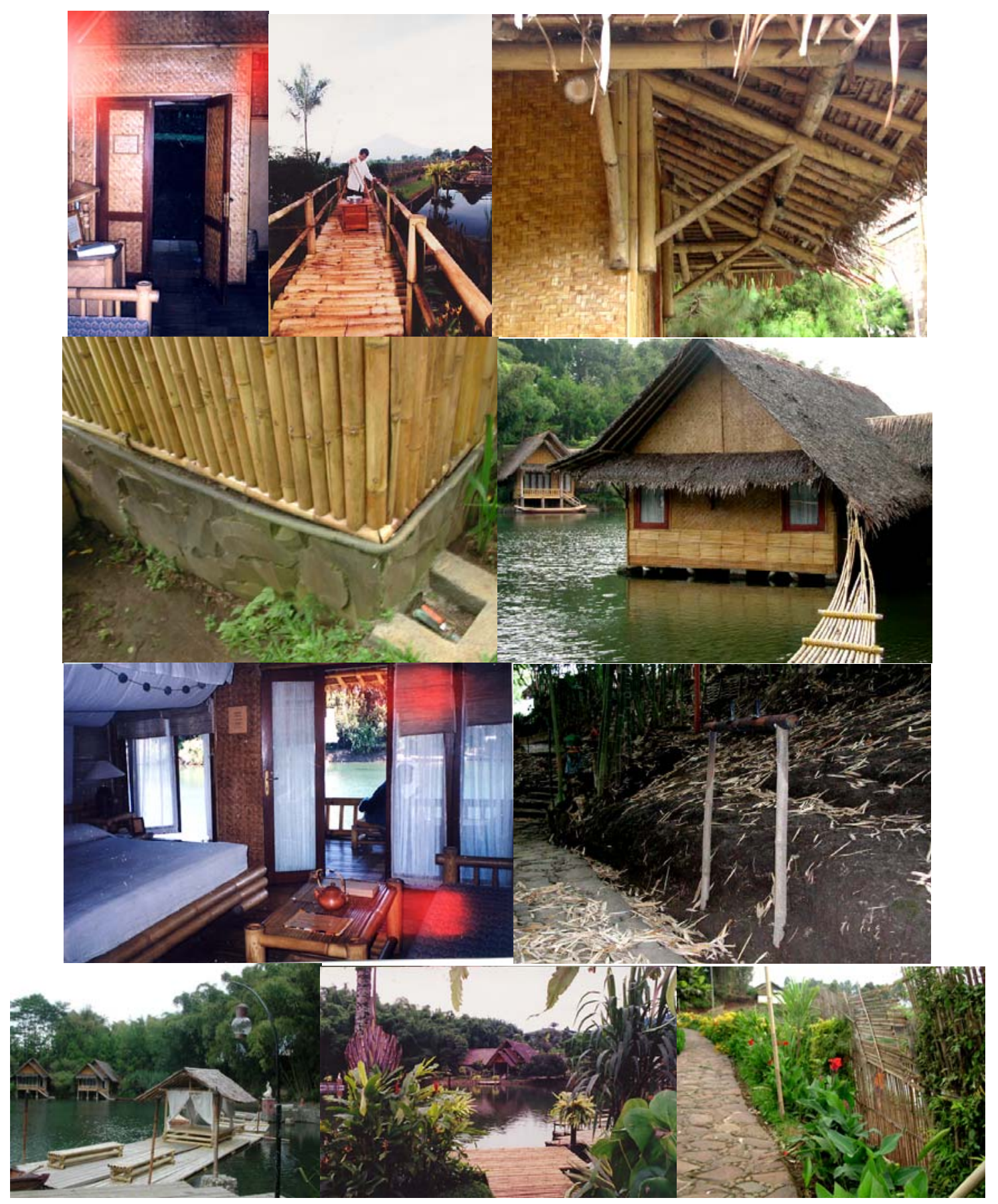

Gambar 12 Penggunaan material bambu dalam berbagai elemen desain baik eksterior maupun interior Resor Kampung Sampireun Sumber: Dokumentasi pribadi

\section{Keterkaitan Aspek Non-Fisik dalam Desain}

Keterkaitan aspek non-fisik dalam desain Resor Kampung Sampireun meliputi sisi orientasi, simbolisme, hierarki, ritual, dan sistem kemasyarakatan. 


\section{Orientasi}

Kepercayaan yang dimiliki oleh masyarakat Sunda terhadap keberadaan matahari mempengaruhi sebagian besar penempatan orientasi bangunan-bangunan yang terdapat di resor Kampung Sampireun ini. Meskipun massa bangunannya sendiri telah mengalami beberapa modifikasi berdasarkan tuntutan bentuk tapak, fungsional, serta estetika. Tetapi bukaan jendela paling banyak menghadap arah utara-selatan.

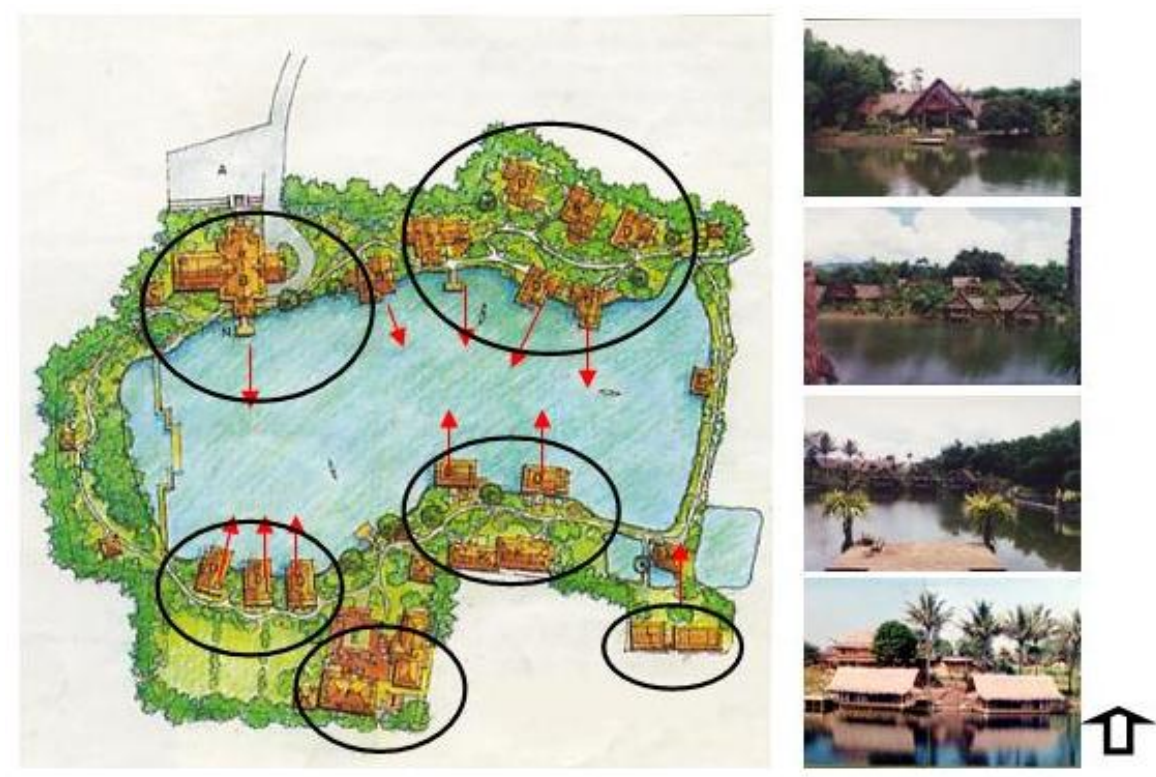

Gambar 13 Pola Orientasi bangunan-bangunan dengan arah bukaan ke utara-selatan, berdasarkan kepercayaan masyarakat Sunda pada dualisme Sumber: Dokumentasi pribadi

\section{Simbolisme}

Pada Resor Kampung Sampireun ini representasi dualisme yang ada dalam kepercayaan masyarakat Sunda terlihat diterapkan pada pola ruang denah cottage tipe waluran tersebut. Namun dalam penerapannya tidak ada pembatas yang membatasi kedua ruang tersebut. Hal ini mungkin terjadi karena konteks dapur pada rumah adat tradisional Sunda yang cenderung kotor, berbeda dengan keberadaan dapur masa kini yang bisa tampil lebih bersih, sehingga keberadaannya bisa menjadi satu dengan ruang keluarga(tengah imah). Selain dua jenis ruang tersebut terdapat juga ruang yang dianggap netral yaitu ruang tidur (enggon) serta kamar mandi (jamban).

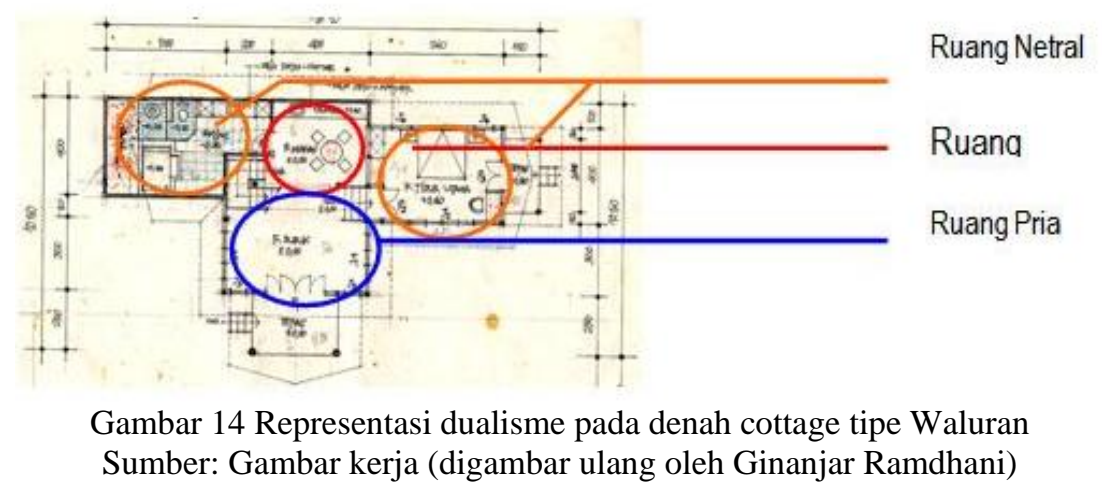


Sedangkan pada dua tipe yang lain tidak terdapat pembagian tersebut, hal ini dikarenakan tidak adanya ruang dapur, serta ruangan kamar (enggon) yang menjadi satu dengan ruangan keluarga (tengah imah).

\section{Hierarki}

Penerapan pola hierarki terlihat pada penempatan massa bangunan mesjid yang diletakan pada bagian ujung barat tapak. Posisi ini mengingatkan kita pada penempatan masjid pada suatu kampung Sunda yang terletak diujung sebelah barat kampung. Hal ini menggambarkan keberadaan mesjid yang lebih tinggi tingkatannya dari bangunan yang lain.
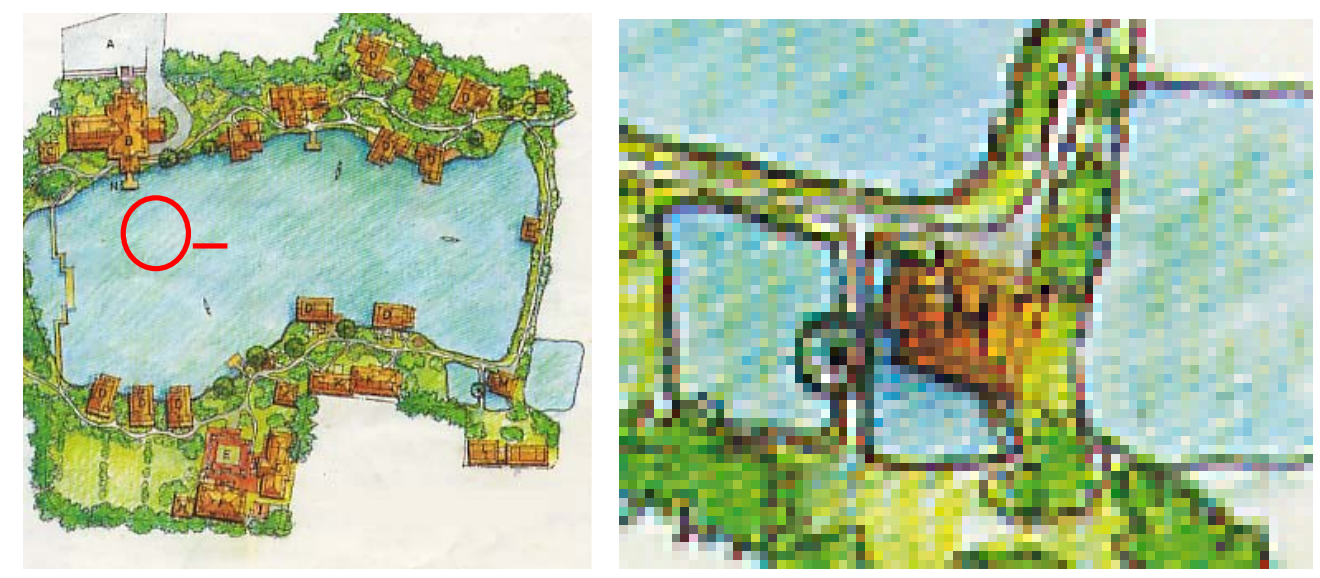

Gambar 15 Keberadaan Masjid yang Berada di Ujung Barat Kompleks Resor Kampung Sampireun.

\section{Ritual}

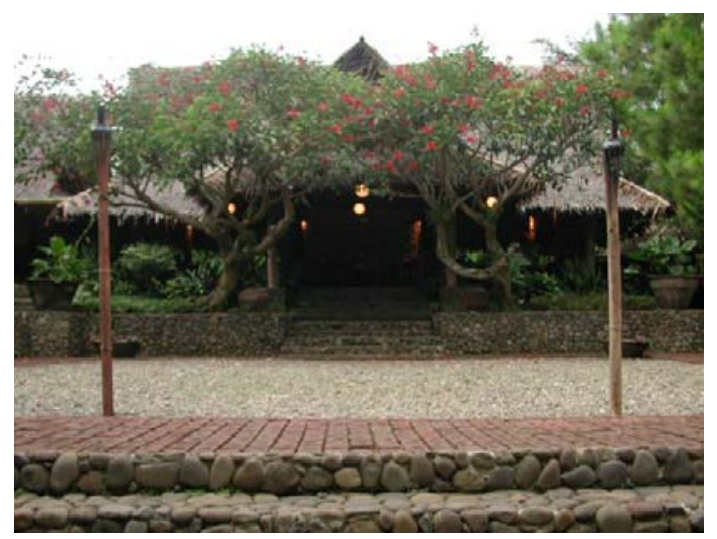

Gambar 16 Taman Pasir Angin sebagai representasi alun-alun pada kampung Sunda

Sumber: Dokumentasi pribadi

Keberadaan Taman Pasir Angin pada Resor Kampung Sampireun ini merupakan representasi keberadaan alun-alun pada kampung Sunda yang biasa digunakan untuk melangsungkan hajat atau kegiatan yang sifatnya bersama. Taman Pasir Angin ini digunakan untuk keperluan kegiatan hajatan perkawinan, pagelaran kesenian Sunda, serta kegiatan lainnya yang bersifat raramean. 


\section{Sistem Kemasyarakatan}

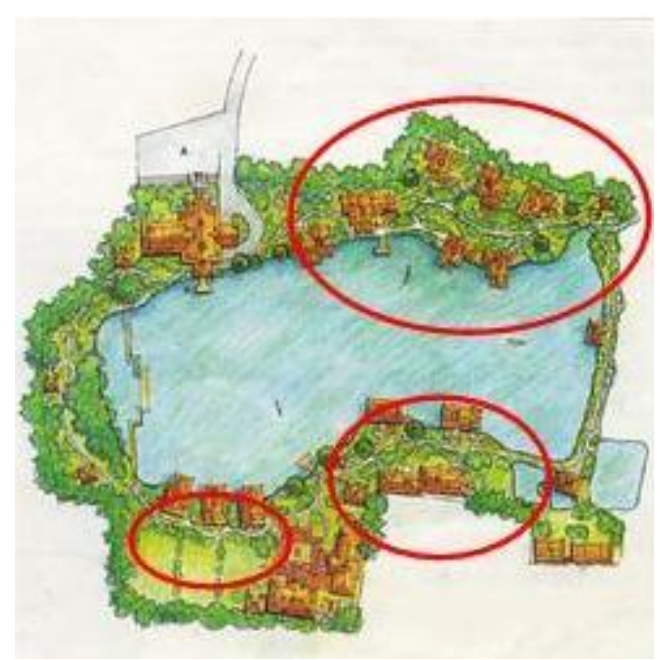

Gambar 17 Tatanan massa cottage yang terpisah dan berkelompok

Seperti telah dijelaskan sebelumnya Masyarakat Sunda pada umumnya tidak biasahidup bersama secara komunal, hal ini disebabkan karena pusat kehidupan masyarakat Sunda adalah keluarga batin yang sifatnya individual. Hal ini mempengaruhi tatanan rumah yang tersebar dan berkelompok karena satu rumah hanya ditempati oleh satu kepala keluarga. Tradisi ini diungkapkan dalam bentukan serta tatanan cottage yang berkelompok, dimana satu cottage hanya cukup untuk satu keluarga.

\section{PENUTUP}

Contemporary Vernacular dalam Arsitektur yang terungkap dalam karya Interior dan Arsitektur yang dijadikan objek studi bahwa adanya suatu usaha yang dilakukan oleh Desainer dan Arsitek sebagai suatu komitmen kesadaran diri untuk mengangkat suatu tradisi yang terdapat di dalam masyarakat Sunda, sebagai reaksi atau tanggapan unik terhadap iklim dan tempat, lalu selanjutnya adalah untuk mengangkat nilai-nilai formal dan identitas simbolis yang ada tersebut ke dalam suatu bentukan baru yang kreatif melalui pandangan Arsiteknya, yang sesuai dengan keadaan sesungguhnya serta nilai-nilai kemanusiaan yang ada dan berkembang pada masa kini.

Wacana ini merupakan bagian dari gerakan Regionalisme yang telah berkembang di Asia khususnya Asia Tenggara, sebagai suatu eksistensi dalam menghadapi international style. Ada empat strategi yang bisa dilakukan dalam mengungkapkan suatu tradisi yang ada dalam Interior dan Arsitektur di antaranya adalah (1) reinvigorating tradition: evoking vernacular, pengungkapan tradisi yang dilakukan dengan cara memperkuat atau menyegarkan tradisi yang telah ada sehingga membangkitkan kembali kesan lokalitas yang telah ada; (2) reinventing tradition: the search for new paradigma, pengungkapan tradisi yang dilakukan dengan cara menemukan atau menggali kembali tradisi yang telah ada sebagai usaha pencarian untuk menemukan suatu paradigma baru; (3) extending tradition: using the vernacular in a modified manner, pengungkapan tradisi yang dilakukan dengan mengembangkan tradisi yang telah ada serta menerapkannya dalam cara yang lain; dan (4) reinterpreting tradition: the use of contemporary idioms, pengungkapan tradisi yang telah ada, ditafsirkan kembali melalui langgam masa kini. 
Gambaran arsitektur vernakular Sunda masa kini sejalan dengan gambaran arsitektur vernakular Sunda pada masa lampau, di mana bentukan interior dan arsitektur yang muncul merupakan bentukan interior dan arsitektur yang bersahabat dengan alamnya. Semuanya tercermin dalam bentukan desainnya, di mana desain muncul bukan sebagai sesuatu yang individualis dan arogan, tetapi membaur serta memperhatikan keberadaan alamnya.

\section{DAFTAR PUSTAKA}

Ching, F. D.K. (1999). Arsitektur, bentuk, ruang \& susunannya. Jakarta: Erlangga.

Holt, C. (2000). Melacak jejak perkembangan seni di Indonesia. Bandung: Arti Line.

Lim, W. S. W., \& Beng, T. H. (1998). Contemporary vernacular: Evoking traditions in Asian architecture. Singapore: Select Books.

Sobur, A. (2003). Semiotika komunikasi. Bandung: Remaja Rosdakarya.

\section{RIWAYAT PENULIS}

Doni Morika lahir di kota (Bukittinggi) pada (31 Desember 1980). Penulis menamatkan pendidikan S1 di (Universitas Katolik Parahyangan) dalam bidang (Arsitektur) pada (2005), S2 di (Institut Teknologi Bandung) dalam bidang (Desain Interior). Saat ini bekerja sebagai (Dosen) di (Universitas Bina Nusantara). Penulis aktif di (Tritis.CO) sebagai (Arsitek \& Desainer Interior). 